\title{
The role of public health students in health advocacy
}

\author{
Tara Prasad Aryal ${ }^{*}$ \\ ${ }^{1}$ Maharajgunj Medical Campus, Institute of Medicine, Tribhuvan University, Kathmandu, Nepal
}

Received:

22 January 2016

Revised:

20 February 2016

Accepted:

11 March 2016

\section{*Correspondence: tarapsdaryal23@gmail.com Maharajgunj Medical Campus, Institute of Medicine, Tribhuvan University, Kathmandu, Nepal.}

Advocacy in public health aims to enhance health and protect health rights of people as universally declared by the United Nations, gaining public and political commitment in health, influencing policy and decision making processes and ultimately strengthen country's health system $(1,2)$. Most notably, it consists of organized actions aimed at changing the major structural and attitudinal barriers to health. In addition, it acts as justice and equity tool in public health. Protection of the vulnerable people and empowerment of disadvantaged population are two underpinning goals of health advocacy. However, the Ottawa Charter for Health Promotion, 1986 connotes advocacy as among advocating, mediating and enabling strategies. World Health Organization later emphasized advocacy for health as, 'a combination of individual and social actions designed to gain the political commitment, policy support, social acceptance and systems support for a particular health goal or program (3).Widespread evidences of public health advocacy include tobacco control legislations, success in polio eradication, burgeoning movement for non communicable disease (NCD) control policy, Vision 2020 initiative, Kathmandu Declaration on Protecting Health Facilities from Disasters, formulation of strategic regional elimination of Kalazar, and improved health outcomes of Millenium Development Goals (4-6).

Advocacy has been extensively used by government, advocacy groups, public health associations, academic institutions. More recently therole of academic students is highly acknowledged at local, national and international level. Successful examples of student's public health advocacy efforts includes abound areas of public health such as tobacco control in educational institution and workplaces (7), Hepatitis B initiative (8). Moreover, recognizing the role of students, the Boonshoft Physician Leadership Development Program has an integrated, comprehensive curriculum on leadership education for medical students which includes a focus on planning, implementing and evaluating health advocacy and field experience (9).

There are different roles public health student can play during advocacy. Firstly, public health student can be representative of the communities they belong to. They can also be enabling agent to raise the voice of youths and other vulnerable people. Lastly, they can be a role model in demonstrating best health practices to people and policy makers (10).

Advocacy initiatives by students are increasing day by day in Nepal, but they are in incipient stage. It generally occurs through small coalitions, groups, student's circle and associations at local and national level (11). They are involved in many awareness campaigns, policy level debates and discussions, addressing health issues at local and national levels, coordinating with media to frame the public health problem and its solution. Also, most the school students are involved in rallies and anti-health protest on anti-tobacco campaigns etc.

In 2071, successful advocacy effort to save public health profession in government was initiated by small network of students and public health advocates (12). Lobbying ministers for a separate public health council to accredit public health graduates and assigning public health graduates as focal person in district public health program and administrative tasks are few of their pressing agendas. The ongoing advocacy by medical students to decentralize medical education and health services close to the community is being supported by students from other health related fields, professionals and associations (13).

However, there are unique challenges that occur at individual, service and policy level advocacy for public health students. Most often, they find health advocacy as a huge task, out of their competency, time consuming and requiring professional status. In essence, it barely remains a sub discipline of public health academia (13).With no or little education and training for students, advocacy remain a complicated issue in multisectoral and multidisciplinary area of health. In addition to this lack of logistic resources and challenges in collaboration with government and its sublets and poor appreciation of student's advocacy efforts are other hurdles leading to demotivation among the students. Likewise, at policy level, majority of the governmental health professionals are indifferent towards it while few of the concerned ones are still unable to put students' voices in policy making process. Meanwhile, building up coalitions and networks from other sectors like education, agriculture, finance remain as key challenges to address broader health issues.

These challenges call for imperative advocacy actions to address public health issues to have impact at individual, community and policy level. Advocacy by building unified coalitions and group, enhancing 
alliances and coordination, forming independent student's body and committee increase support and credibility (14, 15). This leads to better access to media, stakeholders, politicians, policy-makers and sharing of information, costs and resources. In addition to these, involving students in public events and consultation, meetings, media coordination, awareness campaigns provide learning, experience sharing and impact creating platform. Likewise, at academic level, teaching integrated with health advocacy is useful strategy to build competencies among public health students to engage them in lobbying with government, build relationships and make changes at a policy level (16).

\section{Conclusion}

Advocacy is identified as powerful tool to promote actions on the social determinants of health. Various evidences around the globe emphasize that advocacy actions by students can have positive implications on population's health. Continuous and coordinated advocacy initiation by students can help to assure healthy public policy, translate evidence based policy into practices including research, help decision making in allocation of resources, develop student's career and ultimately stand as a role model which overall helps in improving health of the nation.

\section{References}

1. Wise M. The role of advocacy in promoting health. Promot Educ 2001;8:69-74. doi: 10.1177/102538230100800204

2. Johnson SA. Public health advocacy, Edmonton, Canada: Healthy Public Policy Discussion Paper, Alberta Health Services; 2009. Available at: http://www. albertahealthservices.ca/poph/hi-poph-hpp-public-health-advocacy.pdf (Accessed on January 20, 2016.)

3. World Health Organization. Ottawa Charter for Health Promotion. First International Conference on Health Promotion, Ottawa, Canada, 21 November;1986 Available at: http://www.who.int/healthpromotion/conferences/previous/ottawa/en/index3.html (Accessed on 20 Janauary, 2016)

4. World Health Organization. A Decade of Public Health Achievements in WHO's South-East Asia Region: 2004-2013. Availabe at: http://apps.searo.who.int/ PDS_DOCS/B5003.pdf (Accessed on January 20, 2016)

5. Chapman S. Public health advocacy and tobacco control. Making smoking history. Oxford, UK: Blackwell Publishing, 2007.

6. World Health Organization: Stop the Global Epidemic of Chronic Disease. A Practical Guide to Successful Advocacy,2006 Available at: http://apps.who.int/iris/ handle/10665/43513 (Accessed on January 20, 2016)

7. Chapman S, Wakefield M. Tobacco control advocacy in Australia: reflections on 30 years of progress. Health Educ Behav 2001 Jun 1;28(3):274-89. doi: $10.1177 / 109019810102800303$

8. Hsu L, DeJong W, Hsia R, Chang M, Ryou M, Yeh E. Student leadership in public health advocacy: lessons learned from the Hepatitis B Initiative. Am J Public Health. 2003;93(8):1250-1252. doi: 10.2105/AJPH.93.8.1250

9. Crites GE, Ebert JR, Schuster RJ. Beyond the dual degree: development of a five-year program in leadership for medical undergraduates. Acad Med. 2008 Jan 1;83(1):52-8. doi: 10.1097/ACM.0b013e31815c63b6

10. Apfel F. Promoting health: advocacy guide for health professionals. Geneva: International Council of Nurses;2008. Available at: http://www.whpa.org/ppe_ advocacy_guide.pdf. (Accessed on January 20, 2016)

11. Adhikari TB, Mishra SR.The Current Challenges and Role of PHM in Advocacy of Health for All in Nepal, Available at: http://www.phmovement.org/en/node/8030 (Accessed on 20 January, 2016)

12. Swasthykhabar patrika. Janaswasthya adhikrit ko parikshya dine baato khulla, Available at: http://swasthyakhabar.com/2014/07/12759.html (Accessed on 20 Janauary, 2016)

13. Republica. Heed the call, Available at: www.myrepublica.com/editorial/story/26268/heed-the-call.html (Accessed on 20 Janauary, 2016)

14. Chapman S.Advocacy in public health: roles and challenges Int. J. Epidemiol. 200130 (6): 1226-1232. doi:10.1093/ije/30.6.1226

15. Wolff T. A practitioner's guide to successful coalitions. Am J Community Psychol. 2001;29:173-191. doi:10.1023/A:1010366310857

16. Goodhart FW. Teaching advocacy to public health students: The New Jersey experience. Health Promot Pract. 2002 Jul 1;3(3):341-6.doi: 10.1177/152483990200300302 